\title{
The Electrocardiogram in the Preoperative of Low Risk Surgeries: The Responsibility of the Cardiologist
}

\author{
Priscilla da Silva Maia ${ }^{1}$, Isabelle Mendes Rodrigues Salomão ${ }^{1}$ and Ana Luisa Rocha Mallet ${ }^{1,2 *}$ \\ ${ }^{1}$ Estácio de Sá University, Rio de Janeiro, Brazil
}

${ }^{2}$ Federal University of Rio de Janeiro, Rio de Janeiro, Brazil

Submission: March 29, 2018; Published: June 25, 2018

*Corresponding author: Ana Luisa Rocha Mallet, Estácio de Sá University, Rio de Janeiro, Brazil, Email: alr.mallet@gmail.com

\begin{abstract}
Low risk surgeries are many times followed by a request of a number of preoperative exams, including the electrocardiogram, without bringing any advantages to the patients. In this article we discuss some reasons for this practice and present the main cardiology guidelines about the electrocardiogram request for low risk surgeries. Finally, we give some suggestions to try to change this reality that does not bring any advantage to the patients and that almost always delay the surgeries
\end{abstract}

Keywords: Per-operative period; Electrocardiography

\section{Introduction}

In medicine, and in particular in cardiology, many measures known to be beneficial to patients are not used in the expected ratio. On the other hand, other situations known to be inadequate to the good medical practice perpetuate. In this article we will deal with the excessive preoperative tests request of patients that will be subjected to low-risk surgical procedures. Preoperative evaluation of patients undergoing non-cardiac surgeries should

determine the risk of occurrence of complications based on three main points: the risk inherent in the procedure, the risk associated to the patient and the risk determined by the degree of urgency of the surgery. There are no major controversies regarding classification of risk related to the surgical procedure, these being divided into low, intermediate procedures and high risks and presenting respectively chance of complications less than $1 \%$ between 1 and $5 \%$, and more than $5 \%$ (Table 1).

Table 1: Classification of surgical procedures as operative risk.

\begin{tabular}{|c|c|c|}
\hline Low Risk & Intermediate Risk & High Risk \\
\hline Procedures superficial & Kidney transplant & Liver or pulmonary transplantation \\
\hline Thyroid & $\begin{array}{c}\text { Intraperitoneal: splenectomy, hiatal } \\
\text { hernia repair, cholecystectomy }\end{array}$ \\
\hline Cataract & $\begin{array}{c}\text { Correction endovascular abdominal } \\
\text { aortic aneurysm }\end{array}$ & Surgery of bile duct \\
\hline $\begin{array}{c}\text { Urologic minor (ex: transurethral } \\
\text { resection of prostate) }\end{array}$ & $\begin{array}{c}\text { Urologic or gynecology largest } \\
\text { Orthopedic minor (meniscus) }\end{array}$ & Major orthopedic (hip, spine) \\
\hline Dental & Head and neck & Total cystectomy \\
\hline $\begin{array}{c}\text { Asymptomatic carotid (endarterectomy } \\
\text { or stenting) }\end{array}$ & $\begin{array}{c}\text { Patients symptomatic carotid artery } \\
\text { (endarterectomy or stenting) }\end{array}$ & Esophagectomy \\
\hline Breast & Neurological & Aorta and major vascular surgery \\
\hline Minor gynecologic & Peripheral artery angioplasty & Repair of largest viscera \\
\hline
\end{tabular}


As for the moment of surgery there is no controversy about the lower risk of an elective surgery compared to urgent/emergency surgery, when the surgery is usually performed without further investigation, because the risk of not accomplishing it supplants the risk of waiting for an investigation for better risk stratification of patients. On patient assessment in a preoperative non-cardiac elective surgery is where we find the major controversies, including the index to be used to define the risk of the patient and the exams that must be requested. The index that has been most widely used in preoperative assessment of patients undergoing elective surgeries is the index of Lee-also called RCRI (Revised Cardiac Risk Index score) [1], validated in the preoperative risk evaluation for an major adverse cardiac event (AMI, agude pulmonary edema, sudden death, VT/VF, heart block). The indexes of Lee is particularly attractive for use only six variables for this risk assessment and present a good correlation with the risk of the events cited above.

\section{The Current Situation}

In clinical practice we see an excessive request of examinations that in nothing alter the patient's surgical approach. Some extreme examples: a patient 63 years old, healthy, asymptomatic, without any prior history needs a cataract surgery and are requested: CBC, urea, creatinine, glucose, potassium, sodium, chest x-rays and electrocardiogram, in addition to TTP and PT. Another example: a 80 years old woman, with severe Parkinson's disease making her totally dependent, with ascending aorta aneurysm of $6.5 \mathrm{~cm}$, with lung neoplasia diagnosed six months ago who has great pleasure in reading but have bilateral cataracts. Is decided to carry out cataract surgery. But, unfortunately, the patient is not spared of the execution of all tests mentioned above and of all the annoyances that involved it without any practical change in the decision!!!

How did we get to this situation and how a situation so odd perpetuates in the era of the so-called evidence-based medicine? In famous article from 2003, Smetana \& Macpherson [2] have questioned this practice of preoperative tests and remind us how is set the "normality" in the tests that assess continuous variables: out of a population of people without a known disease, $5 \%$ will have exams considered "freaks" $2.5 \%$ in lower range and $2.5 \%$ in upper range). Thus, the probability that there is at least one abnormal exam if 20 are requested is $64 \%$, even in a patient without the disease [2]. In other words, the widespread practice of exam request (and here we're not talking about just the preop), leads to many false positive results, which will lead to the new request tests often invasive and potential complications.

This same article is very happy to discuss the main theoretical reasons for preoperative tests request: the possibility of being detected abnormalities that could interfered on morbidity and mortality and legal reasons (increasingly in focus in the era of medicine the defensive that we experience). But we know that in a low-risk surgery in which the clinical history and physical examination do not detect any unstable condition, the complementary examinations, even if amended, do not interfere with the completion of the surgery. So we're just left with the legal argument. However, 30 to 60 percent of changes found in preoperative examinations are ignored and in half of these situations, the abnormality is not even noted in the schedule or patient records. That is, in case of any complications we will be in a situation even more complicated and more chance of being prosecuted.

With regard more specifically to electrocardiogram, it is estimated that in $30 \%$ of preoperative EKG performed there is some abnormality, but that most of them is not significant to the point that change the surgical plan (especially in the low surgery risk), as updates to overhead of cavities, branch, ST-T changes. And the evolution is not modified after surgery among patients with normal EKG and EKG changes [3]. It certainly made the guidelines clear: it is not indicated the realization of an EKG in low-risk surgery preoperative in asymptomatic patients, being considered class III (not recommended) by Brazilian Society of Cardiology [4], by the American Society of Cardiology [5] and by the European Society of Cardiology [6].

\section{Suggestions}

Some measures could contribute to a change in the behavior in the preoperative tests request:

a) Medical entities of Cardiology, Anaesthesiology and Internal medicine should be involved in the dissemination of existing guidelines. Congresses of this entities are important for discussion of topics so frequently in clinical practice and often don't get as much prominence as themes that involve technological innovations and use of new drugs.

b) Educational institutions should give more importance to this topic in medical training as in the disciplines of surgery, internal medicine and cardiology and in discussions during the internship.

c) Teachers and doctors should discuss with patients and students the relevance of exams for the release of a surgery.

\section{Conclusion}

We believe that these measures could contribute to a change in attitude of doctors in relation to indiscriminate request surveys, in particular, of the electrocardiogram. This fairly widespread culture certainly don't change quickly but we have to take in our daily medical practice steps that can contribute to a change that certainly will benefit the patients and will decrease the pressure for preoperative unnecessary exams particularly in low-risk surgery.

\section{References}

1. Lee TH, Marcantonio ER, Mangione CM, Thomas EJ, Polanczyk CA, et al. (1999) Derivation and prospective validation of a simple index for prediction of cardiac risk of major noncardiac surgery. Circulation 100(10): 1043-1049. 
2. Smetana GW, Macpherson DS (2003) The case against routine preoperative laboratory testing. Med Clin North Am 87(1): 7-40.

3. Ajimura FY, Maia ASSF, Hachiya A, Watanabe AS, Nunes Mdo P, et al. (2005) Preoperative laboratory evaluation of patients aged over 40 undergoing elective non-cardiac surgery. Sao Paulo Med J 123(2): 5053.

4. Gualandro DM, Yu PC, Calderaro D, Marques AC, Pinho C, et al. (2011) II Diretriz de Avaliação Perioperatória da Sociedade Brasileira de Cardiologia. Arq Bras Cardiol 96(3): 1-68.

5. Fleisher LA, Fleischmann KE, Auerbach AD, Barnason SA, Beckman JA, et al. (2014) ACC/AHA guideline on perioperative cardiovascular evaluation and management of patients undergoing noncardiac surgery a report of the American college of cardiology/American heart association task force on practice guidelines. Circulation 130(24): 2215-2245.

6. Kristensen SD, Knuuti J, Saraste A, Anker S, Bøtker HE, et al. (2014) ESC/ ESA Guidelines on non-cardiac surgery: cardiovascular assessment and management The Joint Task Force on non-cardiac surgery: cardiovascular assessment and management of the European Society of Cardiology (ESC) and the European Society of Anaesthesiology (ESA). Eur Heart J 35(35): 2383-2431.

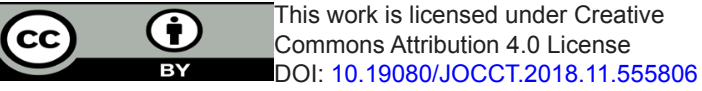

- Quality Editorial service

- Swift Peer Review

- Reprints availability

- E-prints Service

- Manuscript Podcast for convenient understanding

- Global attainment for your research

- Manuscript accessibility in different formats

( Pdf, E-pub, Full Text, Audio)

- Unceasing customer service

Track the below URL for one-step submission https://juniperpublishers.com/online-submission.php 